\title{
Buyer-Seller Relationships in International Trade: Do Your Neighbors Matter? ${ }^{1}$
}

\author{
Fariha Kamal ${ }^{2}$ \\ Center for Economic Studies \\ U.S. Census Bureau \\ 4600 Silver Hill Road \\ Washington, DC 20233, U.S.A \\ fariha.kamal@census.gov \\ +1 (301) 7634575
}

\author{
Asha Sundaram \\ School of Economics \\ University of Cape Town \\ Rondebosch, Cape Town 7701 \\ South Africa \\ assundar.wk@gmail.com \\ +27(0) 727811813
}

\begin{abstract}
Using confidential U.S. customs data on trade transactions between U.S. importers and Bangladeshi exporters between 2002 and 2009, and information on the geographic location of Bangladeshi exporters, we show that the presence of neighboring exporters that previously transacted with a U.S. importer is associated with a greater likelihood of matching with the same U.S. importer for the first time. This suggests a role for business networks among trading firms in generating exporter-importer matches. Our research design also allows us to isolate potential gains from neighborhood exporter presence that are partner-specific, from overall gains previously documented in the literature.
\end{abstract}

JEL Classification: F1, F6, F14, L14, R12

Keywords: exporter-importer match, trade networks, partner-specific spillovers

\footnotetext{
${ }^{1}$ Any opinions and conclusions expressed herein are those of the authors and do not necessarily represent the views of the U.S. Census Bureau. All results havebeen reviewed to ensure that no confidential information is disclosed. ${ }^{2}$ Corresponding author.
} 


\section{Introduction}

In this study, we ask if the presence of exporters selling to a particular foreign buyer in the neighborhood of a firm, which we term a trading network, increases the likelihood of a match between the foreign buyer and the firm. We argue that a network of neighbors can help in numerous ways. First, neighboring exporters can lower the costs of locating a trade partner. Such search costs are a pervasive feature of all cross-border trade transactions, and can be considerable. The growing literature on buyer-seller matches in international trade shows that search costs associated with locating a trade partner are significantly more relevant than either transport costs, or subsequent per-period costs of maintaining the trade relationship (Benguria, 2014; Eaton, Eslava, Jinkins, Krizan, and Tybout, 2013). ${ }^{3}$ In addition, a network can provide access to information to both partners on foreign clients' tastes, navigating foreign institutions, business norms in the destination, reliability of suppliers and their strengths and/or weaknesses, further lowering costs of matching. A network can be particularly important when one or both trading partners are located in a developing country, where information flows are imperfect and reliable information on key activities relating to generating and sustaining a match can be costly to obtain.

We focus on the role of neighboring exporters in a Bangladeshi city that have previously transacted with a particular U.S. importer in facilitating first-time matches between a potential individual Bangladeshi seller and that U.S. importer. We draw upon the networks literature in international trade, namely, Rauch’s (1999) “network/search” view of international trade, the idea that the search process in matching international buyers and sellers is "strongly conditioned

\footnotetext{
${ }^{3}$ Increasing availability of trade dataidentifying both partners in a transaction has resulted in a rich body of work exploring various aspects of buyer-seller relationships in international trade. To name a few, Dragusanu (2014) and Bernard, Moxnes and Ulltveit-Moe(2013) model and provide empirical evidence of assortative matching between exporters and importers in the presence of search costs and trader heterogeneity. Carballo, Ottaviano, and Martincus (2013) document basic characteristics of buyer-seller relationships and develop a model consistent with the findings.
} 
by proximity and preexisting 'ties' and results in trading networks [...]” (p.8). Although we do not measure trading networks in the Rauch sense (Rauch, 1996 and 2001; Combes, Lafourcade, and Mayer, 2005; Aleksynska and Peri, 2014) ${ }^{4}$, our measure of neighboring exporters represents a particular type of trading network - firms that are in the same geographic location selling to the same buyer in the previous period.

We relate the presence of exporters neighboring exporter $i$ and selling to an importer $j$ on first match status, that is the first time exporter $i$ matches with importer $j$. We use confidential transaction level data on U.S. imports in textile and apparel products, henceforth referred to as textile products, from Bangladeshi exporters between 2002 and 2009, sourced from the U.S. Census Bureau. We select textile products because for textile shipments, we observe the manufacturer exporting the product, as opposed to trading agents in the transaction. Further, focusing on trade transactions between the U.S. and Bangladesh is motivated by the need to construct a sensible dataset while focusing on an important bilateral trade relationship. ${ }^{5}$ Bangladesh is the fourth largest apparel exporter to the U.S. ${ }^{6}$ Over three quarters of Bangladeshi exports are in textile and apparel products, with the U.S. being the second largest export destination (Tables 4 and 5, Trade Policy Review, 2012). Exporters in our sample are Bangladeshi textile manufacturing firms, while more than half of U.S. importers are wholesalers and the rest comprise mainly of manufacturing and retail firms.

\footnotetext{
${ }^{4}$ These studies consider two types of networks - social and business. Social networks are typically measured as the stock of bilateral migrants and business networks are typically measured as links between plants/firms belonging to the same business group.

${ }^{5}$ Our research design requires us to analyze all possible trading pair matches and therefore we select a bilateral trade relationship where thenumber of buyers and sellers is relatively small but at the same time captures a significant portion of the economic activity of the trading partner. See Section 3 for further detail on data construction. ${ }^{6}$ See http://www.bdembassyusa.org/uploads/U.S.\%20-\%20BD\%20trade.pdf.
} 
We estimate a linear probability model of the first match status between each Bangladeshi exporter and each U.S. importer over the sample period. A match occurs when the importer and exporter transact for the first time in our sample period. We relate the likelihood of a first match to a measure of exporter presence (or the size of the exporter network) in the neighborhood. The level of detail in the data allows us to exploit variation at the level of the exporter-importer pair, enabling us to fully account for unobservable time-varying exporter and importer shocks that could otherwise induce spurious correlations due to city, buyer or sellerspecific factors.

We believe that our study makes several contributions. First, it exploits the richness of the data to identify a determinant of buyer-seller matches across international borders. Second, it adds to the large literature that examines the determinants of exporter status (Bernard and Jensen, 2004) and highlights the role of neighboring exporters that improve the likelihood of firms exporting to foreign destinations (Koenig, 2009; Koenig, Mayneris, and Poncet, 2010). These studies find that greater presence of exporters selling to a specific foreign destination close to a firm can increase the likelihood that the firm exports to the same destination, and survives in that destination (Fernandes and Tang, 2012 and 2014). The idea is that the presence of exporters nearby exporting to the same destination can lower fixed costs of exporting to a particular country if, in the presence of imperfect information, neighboring exporters facilitate knowledge transfer. Such knowledge includes information on destination-specific business norms and culture, identifying potential trade partners, developing a buyer-supplier relationship, setting up foreign exchange accounts or service centers abroad, or retaining customs agents. ${ }^{7}$

\footnotetext{
${ }^{7}$ Chaney (forthcoming) formalizes the idea that information is a key friction to trade, and develops a general model of the formation of an international network of firms that enables information diffusion. Chaney models the role of trading networks in information diffusion by firms across countries, while in the context of our study, we emphasize the importance of information pertaining to matching with a particular buyer or seller across national borders.
} 
In our analysis, since we examine the role of neighboring exporters on the likelihood of matching with a particular importer, we are able to separately identify information gains that are specific to the trade partner from those specific to the destination country. To the best of our knowledge, there is no existing study that isolates the role of neighbors selling to a particular buyer in a given destination on the probability of matching with the same buyer. By ascertaining if information gains are specific to a trading partner at the firm level, and not just at the country level, we take a step further in the direction of isolating the nature of export spillovers and the channels through which they operate. This can be important for designing trade promotion measures.

Here, we note that either the importer or the exporter (either directly or through a buying house) might initiate the buyer-seller match. ${ }^{8}$ In our empirical analysis, we only observe the match, and not who initiated it or how it was initiated. However, we argue that the presence of neighboring exporters matter in both instances where the importer or the exporter initiates the match. Neighboring exporters may enhance individual matches through various channels. The presence of exporting firms in the neighborhood selling to the same buyer can facilitate information sharing about exporting to that particular buyer. This might include knowledge of any needs of the importer that require customization such as the buyer's product specifications, custom packaging requirements, and/or its clienteles' tastes and preferences.

Additionally, there may be information sharing on locating a buyer or investing in activities that promote an exporter's product to a potential buyer, such as advertising or

\footnotetext{
${ }^{8}$ Buying houses are intermediaries that facilitate matches in numerous ways, for instance, by helping with search or by providing quality certification to buyers. Buying houses could represent one potential channel through which observed networks effects operate. For instance, exporters might learn about one or more of these buying houses from their neighbors. Similarly, a firm located close to other exporters that matched in the earlier period with an importer via a buying house, might be more visible to the buying house. Our conceptual framework allows for the alternative interpretation that buying houses act on behalf of, or substitute for, U.S. importers.
} 
participating in trade shows. The ability to obtain tacit knowledge is likely to lower the fixed and/or variable costs of exporting to a particular buyer. On the importer end, buyers may be more likely to learn about new suppliers when they are located in close proximity to existing suppliers. Buyers might also find it easier to verify product quality, or the likelihood that goods will be supplied on time and as per requirements, when the potential exporter is geographically close, and part of the same business network as the exporter they already transact with.

Results from our preferred specification indicate that a one percent increase in the number of exporters that previously matched to a particular U.S. importer in the neighborhood of a firm is associated with a $0.15 \%$ increase in the likelihood of the firm matching with the same importer for the first time. A comparison with existing studies indicates that our results are economically significant. Results are robust to alternative measures of the neighbor variable, a stricter definition of first time matches, and various other cuts of the data. We also find evidence consistent with information gains or learning being the channel via which network effects operate.

We also provide evidence on the nature of network effects. We find that effects differ by both exporter and importer characteristics. Network effects are concentrated among larger exporters. This result hints at a role for absorptive capacity of the exporter in order to capture benefits from the network. Small exporters may lack the requisite capabilities to translate any information gained from neighbors into actual trade matches. We further find that network effects are stronger when the importer is small relative to when the importer is large. This suggests that U.S. importers vary in their behavior of procuring suppliers. We also present evidence that effects are weaker in cities with more competitive environments, and tend to 
weaken as the number of exporters in a city selling to a particular importer increases, exhibiting congestion effects as exporter presence exceeds a certain threshold.

The rest of the paper is organized as follows. Section 2 presents our empirical model and identification strategy. Section 3 describes the data and measurement of key variables. Section 4 discusses the empirical findings and the final section concludes.

\section{Empirical model and strategy}

In order to motivate our empirical strategy, we assume that exporter $i$ matches with importer $j$ at time $t$ if

$$
\sum_{\tau=0}^{+\infty} \frac{\pi_{i j t+\tau}^{m}}{(1+r)^{t+\tau}}-f_{i j t}>0
$$

where $\sum_{\tau=0}^{+\infty} \frac{\pi_{i j t+\tau}^{m}}{(1+r)^{t+\tau}}$ is the present discounted value of future profits from the match, $r$ is a discount rate and $f_{i j t}$ is the sunk fixed cost of matching that is specific to the match pair $i j$ and time period $t$ when the match first occurs. Assuming that there is no uncertainty over future profits, we can rewrite (2.1) as an exporter $i$ matches with importer $j$ in period $t$ if

$$
\frac{\pi_{i j t}^{m}}{r}-f_{i j t}>0
$$

Profit, $\pi_{i j t}^{m}$, is a function of exporter and importer characteristics, like productivity, destination and origin market-specific factors like aggregate prices of inputs and the final good, and demand in the destination market. We treat each $i j$ match as an independent match decision, which means that the alternative to exporter $i$ not matching with importer $j$ is that the match does not occur.

Within our framework, network effects operate by lowering the sunk fixed cost of matching, which can be considerable. Using U.S.-Colombian trade transactions data, Eaton et al. 
(2013) estimate that the initial search cost of locating one buyer per year is about $\$ 20,642$. The cost drops to $\$ 1,522$ per shipment to maintain each client relationship once the initial match has been established. Thus, the initial cost of matching is a significant portion of total matching fixed costs.

Motivated by evidence of the magnitude of the costs involved in forming exporterimporter relationships, we decompose the initial fixed cost of matching (or the sunk cost) into three components as,

$f_{i j t}=f_{i j t}^{P}+f_{i t}^{D}+f_{j t}^{D}$.

Superscript $P$ denotes partner-specific fixed costs of matching that are specific to each $i j$ pair and superscript $D$ denotes country-specific fixed costs of matching. Country-specific initial period fixed costs include costs of navigating business norms and culture, search costs for a customs or shipping agent, setting up foreign sales or service offices and foreign currency accounts. We allow for the possibility that destination country-specific fixed costs may vary by exporter or importer characteristics over time. Partner-specific initial period fixed costs include costs of searching and advertising, learning about or communicating importers' tastes, clientele, customization or packaging requirements, or exporter capabilities or reliability.

To implement empirically we formulate,

$f_{i j t}=g\left(z_{c j, t-1}\right)+X_{i t}^{1}+X_{j t}^{2}+\varepsilon_{i j t}$,

where $z_{c j, t-1}$ captures the number of exporters selling to importer $j$ in city $c$ at time $t-1, X_{i t}^{1}$ $\left(X_{j t}^{2}\right)$ encompasses exporter-year (importer-year) shocks, and $\varepsilon_{i j t}$ is an idiosyncratic error term.

The key idea is that greater presence in the neighborhood of exporters transacting with a particular U.S. buyer lowers the fixed costs involved for a potential exporter in matching with the same buyer. Evidence from surveys and case studies supports this idea. Egan and Mody 
(1992) document the search process from an importer's point of view. The authors identify primary ways U.S. buyers of bicycle and footwear gather information on potential suppliers in developing countries based on interviews with 28 U.S. importers. They find that U.S. buyers seek information on potential suppliers from within a network of product-specific buyers and suppliers of both final and intermediate goods. They also find information about suppliers at trade fairs and conferences as well as by directly visiting suppliers' factories to assess their capabilities. We argue that this is likely easier if the potential exporter is in the neighborhood of an exporter they already transact with.

Cadot, Iacovone, Pierola, and Rauch (2011) and Eaton et al (2013) provide evidence on the search process from an exporter's point of view. Cadot et al (2011) present findings from survey responses from 395 firms across four African countries. 'Competitor's networks', a measure close to our empirical formulation of neighbors, features in the top three ways in which first time exporters find buyers. Eaton et al (2013) provide references to results from interviews with Colombian exporters that rank activities firms pursued in order to meet potential buyers abroad. These activities include building up an online profile, attending trade fairs, sending sales representatives to visit foreign clients, and maintaining a foreign sales office. Undertaking these activities are likely less costly if firms are able to learn through their business networks.

The probability that exporter $i$ matches with importer $j$ at time $t$ can be written as:

$\operatorname{Pr}\left(\right.$ Match $\left._{i j t}\right)=\operatorname{Pr}\left(\frac{\pi_{i j t}^{m}}{r}-f_{i j t}>0\right)$.

Substituting (2.4) into (2.5) above, we have,

$\operatorname{Pr}\left(\operatorname{Match}_{i j t}\right)=\operatorname{Pr}\left[\varepsilon_{i j t}<f\left(g\left(z_{c j, t-1}\right), X_{i t}^{1}, X_{j t}^{2}, \frac{\pi_{i j t}^{m}}{r}\right)\right]$. 
We estimate a simple linear probability model of the first match, $S_{i j t}$, between exporter $i$ and importer $j$ at time $t$ as follows,

$S_{i j t}=\beta_{1} z_{c j, t-1}+\beta_{2} Y_{i t}^{1}+\beta_{3} Y_{j t}^{2}+\varepsilon_{i j t}$

We define a first match, $S_{i j t}$, as the first time we observe a trade transaction in any textile products between an importer and exporter in a given year within our sample period. Since we are interested in the first match decision, we drop all observations at the exporter-importer level after the year of the first match. We employ a linear probability model similar to Bernard and Jensen (2004) and Fernandes and Tang (2012 and 2014) to estimate (2.7). ${ }^{9}$ In our preferred specification, we include exporter-year, $Y_{i t}^{1}$, and importer-year, $Y_{i t}^{1}$, fixed effects to account for time-varying exporter and importer shocks.

The variable $z_{c j, t-1}$ captures network effects from the presence of exporters to the same buyer $j$ in exporter $i$ 's area $c$ in a previous period. We posit that network effects operate primarily by lowering the sunk costs of matching between an importer and an exporter, after accounting for country-specific sunk costs. Competition and congestion effects could potentially weaken any positive network effects, therefore, we expect $\beta_{1}$ to be strictly positive if network effects dominate.

The time-varying exporter-time specific variables that enter the profit function, like exporter productivity, are absorbed by the exporter-time specific effect, $Y_{i t}^{1}$, as are other unobserved time-varying exporter-specific factors that determine match status. The exporter-time fixed effects also capture destination-specific fixed costs that are common across all U.S. buyers, but vary across Bangladeshi exporters. Thus, we exploit within-city variation in neighbors exporting to each U.S. importer. Finally, given that each exporter is associated with a unique

\footnotetext{
${ }^{9}$ See Fernandes and Tang (2012 and 2014) for a discussion of the choice of a linear probability model over other binary-choice models.
} 
city that does not change over the time period of this analysis, the exporter-time effects also account for city-time specific factors associated with neighborhood exporter presence in the previous period that might result in greater likelihood of matching. This includes unobserved technology or infrastructure quality shocks at the city level, or shocks to product-specific expertise such as the supply of skilled labor that result in specialization in particular products at the city level.

In our preferred specification, we include importer-time fixed effects to operationalize the $Y_{j t}^{2}$ term. These effects control for time-invariant importer characteristics like firm ownership or state level programs aimed at increasing activity of local firms by providing matching services with foreign suppliers, and also for time varying shocks to productivity or subsequent profitability that may influence a trade relationship. In addition, they capture destination-specific fixed costs that are common across all Bangladeshi sellers, but vary across U.S. importers. Thus, we exploit across-city variation in supplier presence for each importer for identification. We also report results for a less demanding specification where instead of importer-year fixed effects we include importer fixed effects and time-varying importer controls, specifically, firm age and employment that are highly correlated with firm productivity (Foster, Haltiwanger, and Krizan, 2001) and subsequently profitability (Helpman, Melitz, and Yeaple, 2004).

In addition to controlling for exporter-year and importer-year fixed effects, we use a lagged measure of nearby exporter presence in order to circumvent spurious correlation with any contemporaneous city-importer-specific unobserved factors. $\varepsilon_{i j t}$ is an idiosyncratic error term. Standard errors in all our specifications are clustered at the importer-city level. 


\section{Data}

\subsection{Source}

The data for this study are drawn from the Linked/Longitudinal Foreign Trade Transactions Database (LFTTD). The LFTTD is a confidential transaction-firm linked database linking individual trade transactions, both exports and imports, to the U.S. firms that make them. ${ }^{10}$ The dataset contains detailed information on trade transactions of a ten-digit Harmonized Commodity Description and Coding system (commonly called Harmonized System or HS) product including the value, quantity, date of transaction, and information about the trading parties.

We focus on the universe of all U.S. import transactions (LFTTD-IMP) that occurred between 2002 and 2009. ${ }^{11}$ Moreover, we only consider all import transactions of textile products from Bangladesh. Textile products include both textile or apparel products as defined under Section 102.21, Title 19, Code of Federal Regulations (CFR) ${ }^{12}$, classified as any products in twodigit HS codes 50 through $63 .{ }^{13}$ In the analysis sample, product codes 61 (knitted apparel) and 62 (non-knitted apparel) account for 96\% of all transactions by value, product code 63 (other textile articles) accounts for 3.5\%, and the remaining product codes account for the rest.

We only consider U.S. textile imports to permit focus on goods-producing exporters and not other trading agents, such as export brokers or freight forwarders, who may have no role in the actual matching process. The identifier for the exporter in the U.S. import transactions database is the manufacturer in case of textile products (see details below), and we exploit this useful feature of the data to circumvent this issue. Textile exports also account for close to $80 \%$

\footnotetext{
${ }^{10}$ See http://www.census.gov/ces/dataproducts/datasets/lfttd.html for more information.

${ }^{11}$ Although, the LFTTD-IMP is available from 1992, we have chosen to focus on the most recent eight-year period for ease of constructing theanalysis dataset. At the time we began the study, 2009 was the latest available year.

${ }^{12}$ See http://www.gpo.gov/fdsys/pkg/CFR-2011-title19-vol1/pdf/CFR-2011-title19-vol1-sec102-21.pdf.

${ }^{13}$ See http://hts.usitc.gov/ for details on each HS chapter.
} 
of total Bangladeshi exports over the sample period and this allows us to capture a significant portion of economic activity of this U.S. trading partner. To a large extent, this also alleviates the concern that exporter presence in the neighborhood in sectors other than textiles might be an omitted variable in our estimation, biasing our estimates.

\subsection{Dataset Construction}

We utilize two sets of firm identifiers in the LFTTD-IMP. The first identifies the U.S. firm (importer) and the second identifies the Bangladeshi textile manufacturer (exporter). The exporter is uniquely identified by the "Manufacturer ID" (MID), a required field on Form 7501, the form U.S. importers are required to file with the U.S. Customs and Border Protection (CBP). ${ }^{14}$ The MID identifies the manufacturer or shipper of the merchandise by an alphanumeric code that is constructed using a pre-specified algorithm with a maximum length of 15 characters (see Table A1 in Appendix A for stylized examples). ${ }^{15}$ For textile shipments, the MID represents the manufacturer only in accordance with Title 19 CFR. ${ }^{16}$ Therefore, our data captures Bangladeshi textile manufacturers rather than trading agents who may or may not engage in the matching decision. The last three characters in the MID designate the city where the manufacturer is located, such that each manufacturer is assigned a MID that uniquely identifies its location.

We perform several basic data checks. First, we exclude transactions between related parties. ${ }^{17}$ Over the sample period, only about $2 \%$ of the total value of trade in textile products between the U.S. and Bangladesh occurs between related parties. Since we are interested in

\footnotetext{
${ }^{14}$ See form http://forms.cbp.gov/pdf/cbp form 7501.pdf.

${ }^{15}$ See Block 13 (pg. 7) for description of MID and Appendix 2 (pg. 30) for instructions on constructing MID at http://forms.cbp.gov/pdf/7501 instructions.pdf.

${ }^{16}$ See http://www.gpo.gov/fdsys/pkg/CFR-2011-title19-vol1/pdf/CFR-2011-title19-vol1-sec102-23.pdf.

1719 U.S.C. $\$ 1401 \mathrm{a}(\mathrm{g})$ outlines seven different ways in which parties may be related in a U.S. import transaction. The ownership-based definition states firms are related if either owns, controls, or holds voting power equivalent to 5 percent of the outstanding voting stock or shares of the other organization.
} 
exploring the role of neighbors on the first match status of a unique trade pair, we exclude trade transactions between the headquarters and subsidiaries of multinational firms. Next, we exclude transactions where the importer or exporter identifiers are missing or where the MID does not conform to the algorithm outlined in the CBP Form 7501 Instructions such as a MID that begins or ends with numeric characters, a MID that is a series of numbers, and the like.

Once the basic data checks are complete, we construct unique trading pairs using the importer and exporter firm identifiers for each year in the sample. There are 2,329 and 8,104 unique number of importers and exporters, respectively, over the sample period. These include Bangladeshi sellers that exported to some U.S. firm and U.S. buyers that imported from some Bangladeshi firm in any year between 2002 and 2009. We then construct the set of 18,874,216 possible trading pairs in any single year. ${ }^{18}$ The final analysis dataset contains observations at the exporter-importer pair and year level permitting investigation of the decision to match with a particular buyer or seller conditional on trade status.

Traders in our sample might be first-time importers or exporters when we first observe them, or might have traded before 2002. In a robustness check, we perform our analysis after retaining solely those exporters who enter the universe of Bangladeshi textile exporters to the U.S. in or after 2002, to ensure that any first-time match we see represents a true first-time match, and not a previous match with a gap in the year 2002. We find that our results are robust to restricting our sample in this manner. Additionally, in a separate analysis, we exclude importers and exporters for the years before which they are born, since a match in these pre-birth years is technically infeasible. For U.S. importers, the year of birth is obtained from the Longitudinal Business Database (LBD), described later in this section. For Bangladeshi

\footnotetext{
${ }^{18}$ This illustrates why we focus on a single sector and trading partner. The need to construct all possible trading pairs precludes considering the universe of U.S. import transactions.
} 
exporters, year of birth is considered to be the first year they appear as exporters to the U.S. after 1992 since we do not have direct information on Bangladeshi firms. Our results remain quantitatively and qualitatively unchanged, and are available upon request.

We can see from the first column of Table 1 that as a share of the number of all possible trading pairs in a year, on average, only about $0.022 \%$ of pairings actually occur. This echoes the broader stylized fact in the trade literature, that trading is a rare activity. Column (2) in Table 1 presents the number of exporter-importer matches that occur for the first time between 2002 and 2009. ${ }^{19}$ The number of first-time matches rises steadily, with a slight drop in the final year, 2009. We can see that about half of all matches are first-time matches. The average (median) duration of U.S-Bangladesh match pairs in our sample is about two and a half (two) years. ${ }^{20}$

In a subsequent analysis, we explore heterogeneity in network effects by importer size. We obtain information on an importer's basic firm characteristics from the LBD that consists of data on all private, non-farm U.S. establishments in existence that have at least one paid employee (Jarmin and Miranda, 2002). There are 2,329 U.S. importers in our sample and we link 2,306 of these to the LBD to obtain information on firm employment, age including year of birth, and sector (manufacturing, retail, wholesale, or other). For firms with multiple plants, age is calculated as the difference between the year of interest and the year of establishment of its oldest plant and the firm is considered to be operating in the sector where the largest share of its employment is housed.

\subsection{Variables}

Since we are interested in examining the role of neighbors in facilitating first time matches, our main independent variable of interest is $S_{i j t}$ that is a dummy variable that takes on a

\footnotetext{
${ }^{19}$ Although all trade pairs are considered first time matches in 2002 as it is the first year of our sample, these observations are excluded from our regressions since we lag our neighbor variable by one period.

${ }^{20}$ The mean and median duration are almost identical if we consider all matches between 1992 and 2011.
} 
value of 1 for the first year $t$ that exporter $i$ and importer $j$ begin trading and 0 otherwise. For instance, if we observe an actual trade transaction between ABC Garments Company in Bangladesh and XYZ Corporation in the U.S. from 2003 through 2007, $S_{i j t}$ takes on value of 1 in 2003 and all other observations in the subsequent years are dropped from the data. All other possible trade pair matches that do not actually take place are assigned zeroes for all years in the sample. Our main explanatory variable of interest, $z_{c j, t-1}$, is the number of other exporters that matched with importer $j$ located in the same area, $c$, as exporter $i$ at time $t-1$ and will be referred to as “\# exporters-importer $j$, same city (t-1)" in the tables.

The geographic area we consider is the city that is reported in the Manufacturer ID. The last three characters of the MID designates the city the manufacturer operates in. We verified the list of cities in our analysis sample against a list of all cities in Bangladesh. Bangladesh is divided into seven administrative divisions that are further divided into 64 districts (zila) and within districts, into 1,009 sub-districts (upazila). ${ }^{21}$ The city information extracted from the MID approximately conforms to sub-districts (see Appendix A and B for further details). Sub-districts are analogous to counties in the U.S. and are the second lowest tier of regional administration. Bangladesh is a small country with an area of about 57,000 square miles, roughly the size of the state of Iowa, and therefore, average area of a sub-district is about 56 square miles. ${ }^{22}$ However, it is a denser country, with the density of population at 1,149 people per square kilometer of land area, relative to 34 for the United States in $2009 .^{23}$

\subsection{Descriptive Statistics}

21 See list of geo codes provided by the Bangladesh Bureau of Statistics at http://www.bbs.gov.bd/WebTestApplication/userfiles/Image/geocodeweb.pdf.

${ }^{22}$ The spillover measures in Koenig (2009) and Koenig et al (2010) are measured at the level of the French employment area that is on average 937 square miles. For a map of the sub-districts of Bangladesh see http://www.fao.org/fileadmin/templates/faobd/img/Administrative Unit Map.jpg.

${ }^{23}$ World Bank, http://data.worldbank.org/indicator/EN.POP.DNST, accessed June 16, 2014. 
Table 2 presents summary statistics on the exporters and importers in our analysis sample. The first column is based on the entire analysis sample and the second and third columns further divide the sample by small and large U.S. importers. "Small" ("large”) importers are those that employ an average of 1-249 (250 or more) employees over the sample period. In our analysis sample, the number of Bangladeshi exporters is more than three times that of the number of U.S. importers. The table shows that an average U.S. importer tends to transact with about six Bangladeshi exporters. There is heterogeneity across small and large importers. Large U.S. importers, on average, tend to transact with about 12 Bangladeshi exporters while small importers match with only four exporters. The average Bangladeshi textile exporter matches with about two U.S. importers and tends to match with a slightly higher number of small importers versus large importers.

This pattern persists at the city level. On average, there are about 24 exporters and 14 importers transacting in a city, with a little less than three times the number of small importers transacting in a city compared to large importers. Our main variable of interest, the number of exporters in a city selling to a particular U.S. importer, is 0.53 on average. Here too, we see differences across small and large importers. The average number of exporters in a city selling to a particular U.S. importer in the previous period is 0.37 in the sample of small importers and increases to 1.42 when the importer is large. We see that an average importer sources from just under two cities, hinting at spatial clustering in buyer-seller matches. Large importers are not very different from small importers. A small U.S. importer sources from about two Bangladeshi cities while a large U.S. importer sources from about three Bangladeshi cities. 


\section{Results}

\subsection{Identifying the role of neighbors in matching individual importers and exporters}

Table 3 presents results from our baseline regression described in equation (2.7). We look at the impact of the presence of firms that previously matched with a U.S. buyer in the neighborhood of a Bangladeshi exporter, defined by a city, on the probability of a first-time match between the same importer and the exporter, successively adding exhaustive fixed effects in each column. Column (1) includes year fixed effects only; column (2) includes exporter-year fixed effects and time-varying importer controls of age and employment; column (3) includes exporter-year and importer fixed effects as well as importer controls and column (4) includes exporter-year and importer-year fixed effects. Column (4) is our preferred specification as it contains the most exhaustive set of fixed effects. ${ }^{24}$

We find that, controlling for exporter-time and importer-time factors that might determine first match status, thereby exploiting within-city variation in exporter matches across importers and across-city variation in exporter matches for each importer, nearby exporter presence is positively associated with the likelihood of a first-time match. From column (4), we find that an additional exporter in the city that previously matched with the same importer is associated with an increase of 0.00006 (with a t-statistic of 9.88) in the likelihood of a first-time match between a Bangladeshi exporter and a U.S. importer. In elasticity terms, our results in column (2) indicate that a one percent increase in the number of exporters in a city selling to a buyer results in a $0.51 \%$ increase in the likelihood of a match with the same buyer for the first

\footnotetext{
${ }^{24}$ We utilize the reg2hdfe module in STATA in order to estimate our linear regression models with two high dimensional fixed effects. See (Guimaraes and Portugal, 2009) for discussion of the algorithm.
} 
time. ${ }^{25}$ This figure drops to $0.19 \%$ after we account for buyer fixed effects and controls, and to $0.15 \%$ once we account for buyer-year effects. ${ }^{26}$

In the context of the literature on export spillovers, we can interpret our results as export spillovers that are specific to the trade partner. Thus, following our discussion in Section 2, our results suggest that partner-specific spillovers are especially beneficial in lowering the sunk costs associated with a particular match. This includes search costs that can be more than thirteen times higher than per period fixed costs of maintaining a trade relationship, as indicated by estimates in Eaton et al (2013).

In order to compare our results to that in the existing literature, and to ensure that our results remain qualitatively similar when we account for the binary nature of our match variable, we implement a conditional logit model as in Koenig et al (2010). We estimate equation (2.7) with exporter-year fixed effects and time-varying importer controls and report the results in Table A2. Koenig et al (2010) search for evidence of export spillovers on a French exporter's decision to start exporting to a particular destination. Implementing a conditional logit model with year and firm-product-country fixed effects, they find that an additional exporter in the neighborhood increases the likelihood of beginning to export to the same destination by 0.16 percentage points. ${ }^{27}$ Our conditional logit estimation results imply that an additional exporter in the neighborhood increases the likelihood of exporting to the same buyer for the first time by

\footnotetext{
${ }^{25}$ Elasticities are calculated using the "margins" command in STATA.

${ }^{26}$ Koenig (2009) finds that a one percent increase in the share of firms exporting to a country increases the probability of exporting to that country by $0.26 \%$. This effect ranges from $0.15 \%$ to $0.33 \%$ when countries are grouped in ascending order of market accessibility.

${ }^{27}$ This result is obtained using an average probability to start exporting in the sample of $30 \%$. See Koenig et al (2010, p. 631) for details. Since we focus on a bilateral relationship (U.S.-Bangladesh) and focus on textile and apparel products, we argue that our exporter-year and importer fixed-effects, in addition to importer controls, render our estimates comparable to Koenig et al (2010) to a reasonable extent.
} 
0.70 percentage points. ${ }^{28}$ Hence, our evidence suggests that spillovers at the firm level are much stronger than destination-specific spillovers, highlighting the importance of isolating spillovers that are partner-specific, and that operate by lowering partner-specific fixed costs of trading.

\subsection{Isolating information gains}

The key idea we explore in this paper is that the presence of neighboring exporters selling to a particular importer increases the likelihood of a firm matching with that same importer, by lowering the fixed costs of matching. We argue that fixed costs are lower because firms learn from their neighbors, or from their network, in myriad ways. Since we cannot directly measure learning, we explore alternate scenarios that might yield an association between exporter presence in the previous period and the likelihood of a first-time match, and show that these scenarios are unlikely.

To begin, we ask if the network effects we observe arise from the large U.S. importers who, when unable to complete their entire order with one Bangladeshi exporter, reach out to other Bangladeshi exporters in the neighborhood in the next period to do so. We note here that even if this were the case, there is no reason, a priori, to expect that the U.S. importer will look to exporters in the same city to fulfill its order.

Nevertheless, under this scenario, network effects would arise solely from having small exporters in the neighborhood. We would not expect to see significant effects when exporters in the neighborhood are large, and are capable of completing orders from large U.S. importers themselves. In addition, we would not anticipate any network effects when the U.S. importer is small. A natural way to explore this idea is to decompose our key neighbor variable into two parts measuring small and large exporter presence in the neighborhood.

\footnotetext{
${ }^{28}$ Marginal effects are calculated using the "margins” command in STATA. We report magnitudes for the 'typical' Bangladeshi exporter and U.S. importer. In other words, effects are calculated with all fixed effects set to zero.
} 
Table 4 presents results for our main specification, with the neighbor variable of interest decomposed into "small" and "large" neighboring exporters in rows (2) and (3) respectively. Exporters are first classified into three quantiles using their average value of total export sales over the sample period. The top quantile is classified as "large" and the rest as "small". Row (2) presents coefficients for the neighbor variable defined as the number of small exporters in the city exporting to the same importer $j$, and row (3) presents coefficients for the neighbor variable defined as the number of large exporters in the city exporting to the same importer $j$. Columns break the sample into "small" and "large" importers. ${ }^{29}$ Column (2) presents results for the sample of small importers and column (3) for the sample of large importers. "Small" ("large") importers are those that employ an average of 1-249 (250 or more) employees over the sample period. Column (1) presents results for the whole sample.

We see from column (3) that network effects exist, and are statistically significant, not only when there is a greater presence of small exporters in the neighborhood, but also when exporters in the neighborhood are large. Additionally, from column (2), we see that network effects exist even when the U.S. importer is small, and is more likely to have its entire order fulfilled by a single Bangladeshi exporter. This is consistent with information gains, and reassures us that our results are not solely driven by lack of exporter capability to fulfill large orders.

In addition, the results in Table 4 help us rule out one other scenario. Consider the case where a large U.S. importer first matches with a Bangladeshi exporter, who then becomes a specialized supplier. This exporter then develops expertise in products customized for this large U.S. importer, generating a barrier to entry for other potential exporters hoping to supply to the

\footnotetext{
${ }^{29}$ We note here that observations in columns (2) and (3) do not add up to observations in column (1) due to the imperfect match between LFTTD-IMP and the LBD that provides importer size information.
} 
U.S. importer. In this case, our estimated coefficient would be an under-estimate, since this scenario would generate a negative relationship between exporter presence (specifically, large exporter presence) in the neighborhood and the likelihood of a first-time match with a large U.S. importer. However, from Table 4, we observe a positive coefficient in row (3), column (3), suggesting that the presence of large exporters in the neighborhood exporting to a large U.S. importer is also associated with greater likelihood of a match with this large importer. Thus, we deem this scenario unlikely as well.

Next, it is possible that U.S. importers gradually expand their presence in the Bangladeshi market, as they test a few relationships with exporters in the initial period, and then recruit an increasing number of exporters in subsequent periods. This type of gradual expansion strategy into a foreign market could induce a positive association between exporter presence in one period, and the likelihood of a match in the next period. However, our results show that a U.S. importer is more likely to match with an exporter if there is a greater presence of exporters that it matched with in the previous period, in the city that this exporter is located in.

If our results purely reflected U.S. importers’ expansion strategy, we would not anticipate this propensity by importers to match in the neighborhood of previous partners. This is especially true for large U.S. importers, who typically operate in more than one Bangladeshi city, and can select exporters from other cities. In column (4), we restrict our estimation sample to large U.S. importers only. ${ }^{30}$ We find that the coefficient on the key neighbor variable is positive and significant, indicating that even large importers, who can potentially match with exporters in any Bangladeshi city, display greater likelihood of matching with an exporter if they have previously

\footnotetext{
${ }^{30}$ Observations in column (4) differ from those in column (3), since in column (3) the decomposition of the neighbor variable leads to certain observations being dropped from the sample. These include instances where we do not observe a small or large exporter in a city exporting to a particular importer.
} 
transacted with other exporters in the neighborhood. This lends further credence to the idea of information gains through the network.

In column (5), we test whether the impact of a higher number of neighbors that previously matched to the same U.S. importer remains significant when we only consider cities where multiple products are produced. This addresses a particular concern that if there are cities that specialize in a product, and there are only certain U.S. importers who import those products, then these importers would have to trade with exporters in particular cities. Subsequently, all exporters in the neighborhood would be solely transacting with particular U.S. importers who demand particular products and our results would be an artifact of this specific scenario. Twodigit HS products 61 and 62 represent about 96\% of all transaction value in our analysis sample. Therefore, we restrict our sample to cities where both product categories are manufactured.

We find from column (5) that, controlling for exporter-time and importer-time specific factors that might determine matches, an additional exporter in the city that previously transacted with a U.S. importer is associated with an increase of 0.00006 (with a t-statistic of 9.85) in the likelihood of a first-time match between a Bangladeshi exporter and the same U.S. importer. This is quantitatively and qualitatively similar to results from our preferred specification in column (4), Table 3.

Finally, we note that the final phase of the removal of textile and apparel quotas under the Multifiber Arrangement (MFA) overlaps with the beginning of our sample period. The MFA phase-down began in 1997 and all quotas were removed in the beginning of 2005. Consider cities that transact in previously quota bound and unbound products. It is possible that the final removal of the MFA quotas in 2005 caused a surge in new matches between U.S. importers and Bangladeshi exporters transacting in previously quota bound products, and resulted in an 
increasing number of new matches in subsequent years. This might induce a positive correlation between matches to particular importers in the previous period and the likelihood of a first-time match in the current period. To ensure that our results are not predominantly being driven by the MFA quota removal, we focus only on those cities that produced exclusively quota bound or exclusively unbound products over our sample period. We classify ten-digit HS products as bound if the quota fill rate for that product was greater than 90 percent in $2004 .^{31}$ Results are presented in column (6) of Table 4. The coefficient on the neighbor variable is 0.000043 and is still statistically significant.

\subsection{Robustness checks}

In this section, we carry out robustness checks of our baseline results presented in Table 3. Results are presented in Table 5. Column (1) of Panel A tests whether the impact of neighbors that previously matched with the same U.S. importer remains significant when the sample is restricted to observations for which the number of neighboring exporters exporting to the same importer is greater than 1, an exercise similar to Koenig et al (2010). The purpose is to ensure that the observed effects are not only due to cases of textile exporters starting to export to a particular U.S. importer following an increase in the number of neighbors from zero to one.

We find that, controlling for exporter-time and importer-time specific factors that might determine matches, an additional exporter in the city selling to the same importer is associated with an increase of 0.000066 (with a t-statistic of 10.34) in the likelihood of a first-time match between a Bangladeshi exporter and a U.S. importer. This is quantitatively and qualitatively similar to results from our preferred specification in Table 3. Our results confirm that the impact

\footnotetext{
${ }^{31}$ We obtain MFA quota fill rates for Bangladesh for 2004 by OTEXA product category, and the concordance between OTEXA product categories and HS product categories from Brambilla, Khandelwal and Schott(2010).
} 
of neighbors remains positive, significant, and almost identical in magnitude when considering observations with more than one neighboring exporter.

In column (2), we restrict the sample to exporters who begin exporting to the U.S. in 2002, the first period in our sample, and after. We first create a list of all Bangladeshi textile exporters between 1992 and 2009 since the LFTTD-IMP is available beginning in 1992. We then only keep the exporters who appear in the data for the first time in 2002 and after. ${ }^{32}$ This is to address the concern that the first-time matches we observe in our data actually took place before 2002, with a gap between 2002 and the first year in which we observe them in our sample period. This would lead us to erroneously classify continuing relationships as a first-time match. Our main result remains quantitatively and qualitatively similar to results in column (4), Table 3 using a stricter definition of first-time matches.

Next, we address the concern that a large share of exporters in our sample may be multiplant exporters. In case of multi-plant exporters, although our independent variable correctly assigns manufacturers to the cities they are located in, it is possible that the headquarter, rather than the manufacturing location of a multi-plant firm, is the unit responsible for developing trade relationships. Since we do not have firm level information for the Bangladeshi manufacturers in our sample to identify multi-plant status of a firm, we offer two reasons why we believe our results are not disproportionately being driven by the presence of multi-plant firms.

First, the export-oriented Bangladeshi textile sector is characterized by a large number of small firms rather than a few large firms (Yamagata, 2007) and large firms are the ones typically associated with multi-unit status. ${ }^{33}$ Second, we rerun our baseline regressions on a restricted sample of small exporters, according to exporters' average sales. It is more likely that units of

\footnotetext{
${ }^{32}$ If any of these exporters had exported to the U.S. pre-1992 we would not be able to capture that information. ${ }^{33} \mathrm{Kim}$ (1999) documents that the number of employees per manufacturing establishment of U.S. firms is 7 to 10 times larger for multi-unit compared to single-unit firms (Table 4).
} 
multi-plant firms will tend to be larger in terms of total export value, and therefore, if the presence of such exporters in our sample is disproportionately driving our results, we would expect network effects to exist only for large exporters. Our results suggest otherwise. In column (3), we restrict our sample to small exporters. Small exporters are exporters in the bottom two quantiles of the distribution of average value of total export sales over the sample period. Our coefficient of 0.000032 is still positive and statistically significant, though it is smaller in magnitude than our baseline in Table 3.

In Panel B of Table 5, we explore alternative measures of our neighbor variable. Columns (1) and (2) present measures of exporter presence in the neighborhood, normalized by the total number of exporters and importers in the city in the previous period, respectively. These measures establish the robustness of our qualitative result after accounting for the fact that exporter density might capture network effects better than the number of exporters in the neighborhood. We find that greater density of firms in the neighborhood exporting to a U.S. importer is associated with a higher likelihood of matching with the same importer, and that these effects are statistically significant.

Finally, column (3) explores an alternative lag structure to our baseline measure. We measure the number of exporters in city $c$ selling to importer $j$ at time $t-2$. The magnitude of the coefficient on the presence of exporters in the neighborhood selling to a U.S. importer two periods previously is still positive and significant, but smaller than our baseline estimate in Table 3.

\subsection{Extensions}

Our goal thus far has been to establish that greater presence of exporters in the neighborhood that matched with a particular importer is associated with a greater probability of 
matching with the same importer. We argue that greater exporter presence in the neighborhood lowers the fixed costs of matching through information gains. To this end, we show that alternate scenarios that might yield observationally equivalent empirical results are unlikely. We also ascertain that our results are robust to alternate measures of exporter presence. In this section, we explore the nature of network effects further.

First, we ask if these effects differ for large and small importers and exporters, motivated by considerable heterogeneity in exporter and importer sizes observed in the data. The average annual value of a transaction between a trade pair in our sample is a little over half a million U.S. dollars. Figure A1 in Appendix A shows the distribution of trade value, in thousands of current U.S. dollars, over our sample period. We can see that about three-quarters of annual Bangladeshi textile export transactions are valued at less than $\$ 500,000$. We expect that large Bangladeshi exporters might benefit from networks differently from small exporters. Specifically, they might have greater capacity to absorb knowledge from their neighbors. Alternatively, small exporters might rely more on neighbors to surmount the fixed costs of matching, and networks might matter more for them.

On the importer side, evidence suggests that there is substantial heterogeneity within U.S. trading firms in terms of size (Bernard, Jensen, and Schott, 2010). The average export value and number of exporters per importer differ vastly by importer size in each of the sample years (see Appendix B, Figures B1 and B2). The average import value of small importers is less than half that of large importers. Large importers also transact with almost twice the number of Bangladeshi exporters compared to small importers, on average. Large firms in the U.S. importing textile products from Bangladesh are likely to behave differently in procuring suppliers and so we expect network effects to differ across size categories. For instance, like 
small exporters, small U.S. importers might be more reliant on their existing suppliers for information on potential future suppliers than large U.S. importers, who might have alternative means of search. Additionally, on the Bangladeshi side, exporters might find it more difficult to search and match with smaller U.S. buyers.

In column (1) of Table 6, we interact our key neighbor variable with a dummy that equals one when the exporter in the match is large. Similarly, in column (2), we interact our key neighbor variable with a dummy that equals one when the importer in the match is large. When included with the main neighbor variable, these interaction terms capture differential effects for large exporters and importers, respectively.

Results in column (1) of Table 6 indicate that network effects are much stronger for large exporters. In fact, we find that the coefficient on the main neighbor variable is much smaller and not statistically significant. These results suggest that large exporters primarily benefit from networks. One reason for this might be that in order to assimilate and exploit information, exporters need some minimum capacity. Small exporters may not have the requisite capabilities to translate any information they gain from neighbors into a match. This idea is akin to that prevalent in the literature on multinational firms and technology transfer to domestic firms, where only domestic firms with sufficient absorptive capacity can gain from spillovers (Blalock and Gertler, 2009).

Alternatively, if the importer is primarily responsible for initiating and finalizing the match, it is possible that larger exporters in the neighborhood are more visible to both the importer and the exporters who matched with the importer in the previous period. We note here that these explanations are speculative, and firmly establishing them will require further work that is beyond the scope of this paper. 
From column (2), we see the coefficient on the interaction between the neighbor variable and the dummy for when the importer is large is negative and statistically significant. This means that smaller importers gain more from network effects (or large importers gain less). This is consistent with the idea that where the onus of matching is on the importer, fixed-costs of matching are potentially higher for small importers than larger ones, and hence it is small importers who benefit.

In Table 7, we examine the network effect as the neighbor variable takes higher values. While exporter presence in the neighborhood can spur matches, the presence of too many neighborhood exporters selling to a particular U.S. importer may increase competition, cause congestion, and lower the likelihood of matching with the importer. In other words, we expect network effects to dissipate as the number of exporters in the city transacting with an importer increases beyond a certain threshold. Column (1) of Table 7 searches for evidence of such congestion effects. The first four rows provide coefficients for interactions of the neighbor variable with dummies that indicate where the value of the variable falls in the distribution. The quantile dummies are created as follows. We disregard the cases where the neighbor variable equals zero. This represents about 75 percent of the observations. We divide the remaining nonzero values into four quantiles. The omitted category includes cases where the neighbor variable equals zero. $^{34}$

Results indicate that the magnitude of the network effect increases as the neighbor variable takes higher values, until approximately the $87^{\text {th }}$ percentile which corresponds to about 3 neighbors, after which it falls. Thus, we find that when the number of exporters in the

\footnotetext{
${ }^{34}$ In our estimation, the neighbor variable, which captures the effect for the omitted category is dropped, sinceit consists solely of zero values.
} 
neighborhood exporting to a U.S. buyer increases beyond a certain value, effects weaken, as congestion potentially begins to overwhelm any positive learning effects.

In column (2), we examine differential network effects in cities where the number of total Bangladeshi exporters per U.S. importer in the previous period is large. The idea is to ask if network effects differ by intensity of competition in the neighborhood. We interact the neighbor variable with the total number of Bangladeshi exporters per U.S. importer in a city in the previous period. Results indicate that network effects are much weaker in cities with more intense competition for importers, suggesting that exporters might guard information more carefully in more competitive environments.

In summary, our results suggest that a one percent increase in the number of textile exporters in a Bangladeshi city that previously matched with a U.S. importer results in a $0.15 \%$ increase in the likelihood of a match between an exporter and the same buyer for the first time. Comparison with existing evidence suggests that this effect is economically significant. We argue that exporter presence in the neighborhood lowers partner-specific fixed costs of matching, and facilitates information sharing. We also present evidence that these effects vary with both exporter and importer characteristics. Network effects are weaker in more competitive environments and dissipate once exporter presence reaches a certain threshold.

\section{Conclusion}

This paper finds a statistically positive and economically significant role for other exporters in the neighborhood of a firm, that have previously matched to a particular importer, in improving the likelihood of that firm matching with the same importer for the first time. Thus, we further build on the existing empirical body of evidence that documents network effects in 
trade and positive export spillovers specific to destinations and products. Our study also contributes to the nascent investigations in the international trade literature on matches between buyers and sellers and their determinants.

Our results establish the importance of isolating the buyer-specific component of export spillovers and recognizing that gains may depend on exporter and importer characteristics. Earlier studies have underscored the role of trade promotion measures that bring about learning and information exchange among potential exporters about destination markets, including prevailing consumer tastes, demand conditions and customs procedures. We find that information externalities at the firm level are significant, and disseminating information on identifying individual buyers and sellers in the foreign country and their requirements and capabilities can help spur trade relationships. Finally, our study underscores the importance of linking firm-trade transactions data between country pairs to shed further light on the determinants of the relationship between buyers and sellers transacting across borders. 


\section{Acknowledgements}

We thank and participants at the 2013 Center for Economic Studies seminar series, European Trade Study Group (Birmingham, U.K.), University of Pretoria (South Africa) seminar series, Annual Research Data Center Conference, Comparative Analysis of Enterprise Data Conference, Midwest International Trade Meetings (Ann Arbor, MI), Annual Meetings of the Society of Government Economists, North American Regional Science Conference, the 2014 U.S. International Trade Commission seminar series, Missouri Economics Conference, Syracuse University seminar series, and the Washington Area International Trade Symposium for helpful comments. Any errors or omissions remain our own. 


\section{References}

Aleksysnka, Mariya, and Giovanni Peri, "Isolating the Network Effect of Immigrants on Trade", The World Economy 37:3 (2014), 434-455.

Benguria, Felipe, "Production and Distribution in International Trade: Evidence from Matched Exporter-Importer Data,” mimeo (2014).

Bernard, Andrew B., and J. Bradford Jensen, “Why Some Firms Export?” Review of Economics and Statistics 86:2 (2004), 561-569.

Bernard, Andrew B., Andreas Moxnes, and Karen Helene Ulltveit-Moe, "Two-sided Heterogeneity and Trade', mimeo (2013).

Bernard, Andrew B., J. Bradford Jensen, and Peter K. Schott, "Wholesalers and Retailers in U.S. Trade,” American Economic Review Papers and Proceedings (2010), 408-413.

Blalock, Garrick, Paul J. Gertler, "How Firm Capabilities Affect Who Benefits from Foreign Technology,” Journal of Development Economics 90:2 (2009), 192-199.

Brambilla, Irene, Amit K. Khandelwal, and Peter K. Schott, “China's Experience under the Multifiber Arrangement and the Agreement on Textile and Clothing”, China's Growing Role in World Trade, Robert Feenstra and Shang-Jin Wei, Ed (2010).

Cadot, Olivier, Leonard Iacovone, Denisse Pierola, and Ferdinand Rauch, "Success and Failure of African Exporters,” Center for Economic Performance working paper 1054 (2011).

Carballo, Jeronimo, Christian Volpe Martincus, and Gianmarco Ottaviano, “The Buyer Margins of Exports,” Center for Economic Performance working paper 9584 (2013).

Chaney, Thomas, “The Network Structure of International Trade,” American Economic Review forthcoming.

Combes, Pierre-Philippe, Miren Lafourcade, and Thierry Mayer, "The Trade-Creating Effects of Business and Social Networks: Evidence from France,” Journal of International Economics 66:1 (2005), 1-29.

Dragusanu, Raluca, "Firm-to-Firm Matching Along the Global Supply Chain," Harvard University working paper (2014).

Eaton, Jonathan, Marcel Eslava, David Jinkins, C.J. Krizan, and James Tybout, “A Search and Learning Model of Export Dynamics,” Pennsylvania State University working paper (2013).

Egan, Mary Lou, and Ashoka Mody, "Buyer-Seller Links in Export Development," World Development 20:3 (1992), 321-334. 
Fernandes, Ana, "Firm-level Productivity in Bangladesh Manufacturing Industries," World Development 36:10 (2008), 1725-1744.

Fernandes, Ana, and Heiwai Tang, “Learning to Export from Neighbors,” mimeo (2014).

Fernandes, Ana, and Heiwai Tang, "Learning from Neighbors' Export Activities: Evidence from Exporters' Survival,” mimeo (2012).

Foster, Lucia, John Haltiwanger, and C.J. Krizan, “Aggregate Productivity Growth: Lessons from Microeconomic Evidence,” (pp. 303-372), In Charles R. Hulten, Edwin R. Dean, and Michael J. Harper (eds.), New Developments in Productivity Analysis, (Chicago: University of Chicago Press, 2001).

Guimaraes, Paulo, and Pedro Portugal, "A Simple Feasible Alternative Procedure to Estimate Models with High-Dimensional Fixed Effects,” IZA discussion paper 3935 (2009).

Helpman, Elhanan, Marc J. Melitz, and Stephen R. Yeaple, "Export Versus FDI with Heterogeneous Firms,” American Economic Review 94:1 (2004), 300-316.

Jarmin, Ron, S., and Javier Miranda, “The Longitudinal Business Database,” U.S. Census Bureau Center for Economic Studies working paper 02-17 (2002).

Kim, Sukkoo. “The Rise of Multiunit Firms in U.S. Manufacturing,” Explorations in Economic History 36, (1999), 360-386.

Klepper, Steven, and Romel Mostafa, "Industrial Development Through Tacit Knowledge Seeding: Evidence from Bangladesh Garment Industry,” Carnegie Mellon University working paper (2009).

Koenig, Pamina, “Agglomeration and the Export Decisions of French Firms," Journal of Urban Economics 66 (2009), 186-195.

Koenig, Pamina, Florian Mayneris, and Sandra Poncet, "Local Export Spillovers in France," European Economic Review 54 (2010), 622-641.

Monarch, Ryan, “It's Not You, It's Me: Breakups in U.S.-China Trade Relationships," University of Michigan working paper (2013).

Rauch, James, "Business and Social Networks in International Trade,” Journal of Economic Literature 39:4 (2001), 1177-1203.

Rauch, James, "Networks versus Markets in International Trade," Journal of International Economics 48:1 (1999), 7-35.

Rauch, James, “Trade and Search: Social Capital, Sogo Shosha, and Spillovers,” NBER working paper 5618 (1996). 
Trade Policy Review, 2012. World Trade Organization, WT/TPR/G/270.

World Bank Indicators, http://data.worldbank.org/indicator/EN.POP.DNST, accessed June 16, 2014.

Yamagata, Tatsufumi, "Prospects for Development of the Garment Industry in Developing Countries: What Has Happened Since the MFA Phase-Out?” Japan External Trade Organization, Institute of Developing Economies discussion paper 101 (2007). 
TABLE 1-UNIQUE MATCHES, BY YEAR

\begin{tabular}{ccc}
\hline Year & All & First Time \\
\hline 2002 & 3,586 & 3,586 \\
2003 & 3,327 & 1,828 \\
2004 & 3,407 & 1,780 \\
2005 & 4,012 & 2,399 \\
2006 & 4,763 & 2,987 \\
2007 & 4,785 & 2,866 \\
2008 & 5,492 & 3,220 \\
2009 & 4,924 & 2,615 \\
$2002-2009$ & & 21,281 \\
\hline
\end{tabular}

Notes: The statistics are based on all U.S.-Bangladesh trade transactions in textile products only; "Matches" refers to unique exporter-importer combinations that have transacted in the given year.

"First Time" refers to matches that occur in the given year that have not occurred in previous years in the sample that spans 2002 through 2009. 
TABLE 2-SUMMARY STATISTICS

\begin{tabular}{|c|c|c|c|c|c|c|}
\hline \multirow[b]{2}{*}{ Variable } & \multicolumn{2}{|c|}{ All Importers } & \multicolumn{2}{|c|}{ Small Importers } & \multicolumn{2}{|c|}{ Large Importers } \\
\hline & Mean & Std. Dev. & Mean & Std. Dev. & Mean & Std. Dev. \\
\hline Number of Exporters/Importer & 5.64 & 14.15 & 4.10 & 7.55 & 12.27 & 27.37 \\
\hline Number of Importers/Exporter & 1.82 & 1.64 & 1.62 & 1.23 & 1.45 & 1.04 \\
\hline Number of Exporters-Importer $j$, Same City & 0.53 & 3.20 & 0.37 & 1.81 & 1.42 & 6.85 \\
\hline Number of Cities/Importer & 1.87 & 1.76 & 1.67 & 1.16 & 2.81 & 3.05 \\
\hline Number of Importers/City & 14.45 & 64.62 & 15.54 & 60.68 & 6.35 & 17.99 \\
\hline Number of Exporters/City & 23.72 & 129.84 & - & - & - & - \\
\hline
\end{tabular}

Notes: Importers are categorized into two size bins using average number of employees over the sample period. “Small” refers to 1-249 employees and “Large” refers to 250+ employees. 
TABle 3-First Match Status, 2002-2009, Role Of Neighbors

\begin{tabular}{lcccc}
\hline & $(1)$ & $(2)$ & $(3)$ & $(4)$ \\
\hline \# exporters-importer j, same city (t-1) & 0.000130 & 0.000132 & 0.000069 & 0.000062 \\
& $(51.83)$ & $(49.07)$ & $(11.21)$ & $(9.88)$ \\
\hline Observations & & & & $131,965,095$ \\
Year Fixed Effect & $131,965,095$ & $99,454,323$ & $99,454,323$ & - \\
Importer Fixed Effect & $\mathrm{Y}$ & - & $\mathrm{Y}$ & - \\
Importer Controls & - & - & $\mathrm{Y}$ & - \\
Importer x Year Fixed Effect & - & - & - & $\mathrm{Y}$ \\
Exporter x Year Fixed Effect & - & $\mathrm{Y}$ & $\mathrm{Y}$ & $\mathrm{Y}$ \\
\hline
\end{tabular}

Notes:T-statistics reported in parentheses based on standard errors clustered at the importer-city level. The dependent variable, "First Match Status", takes on the value 1 in the first year a transaction is observed between a unique exporter-importer pair and is 0 otherwise. The independent variable is lagged one year. Importer controls include logged values of firm age and employment. 
TABle 4-FIRst MAtCh Status, 2002-2009, Ruling OUt Alternative EXPlanations

\begin{tabular}{|c|c|c|c|c|c|c|}
\hline & $\begin{array}{c}\text { All } \\
\text { Importers } \\
(1)\end{array}$ & $\begin{array}{c}\text { Small } \\
\text { Importers } \\
\text { (2) }\end{array}$ & $\begin{array}{l}\text { Large } \\
\text { Importers } \\
\text { (3) }\end{array}$ & $\begin{array}{c}\text { Large } \\
\text { Importers }\end{array}$ & $\begin{array}{c}\text { Cities: } \\
\text { Multi-product }\end{array}$ & $\begin{array}{c}\text { Cities: } \\
\text { Bound or } \\
\text { Unbound } \\
(6)\end{array}$ \\
\hline \# exporters-importer j, same city (t-1) & - & - & - & $\begin{array}{c}0.000050 \\
(6.97)\end{array}$ & $\begin{array}{c}0.000063 \\
(9.85)\end{array}$ & $\begin{array}{c}0.000043 \\
(1.98)\end{array}$ \\
\hline \multicolumn{7}{|l|}{ \# exporters-importer j, same city (t-1) } \\
\hline - Small Exporters & $\begin{array}{c}0.000047 \\
(2.55)\end{array}$ & $\begin{array}{c}0.000044 \\
(1.58)\end{array}$ & $\begin{array}{l}0.000066 \\
(2.71)\end{array}$ & - & - & - \\
\hline - $\quad$ Large Exporters & $\begin{array}{c}0.000072 \\
(8.02)\end{array}$ & $\begin{array}{c}0.000101 \\
(9.54)\end{array}$ & $\begin{array}{c}0.000050 \\
(3.88)\end{array}$ & - & - & - \\
\hline Observations & $124,192,531$ & $103,425,176$ & $19,539,811$ & $20,763,398$ & $128,282,482$ & $2,753,945$ \\
\hline Importer x Year Fixed Effect & $\mathrm{Y}$ & $\mathrm{Y}$ & $\mathrm{Y}$ & $\mathrm{Y}$ & $\mathrm{Y}$ & $\mathrm{Y}$ \\
\hline Exporter x Year Fixed Effect & $\mathrm{Y}$ & $\mathrm{Y}$ & $\mathrm{Y}$ & $\mathrm{Y}$ & $\mathrm{Y}$ & $\mathrm{Y}$ \\
\hline \multicolumn{7}{|c|}{$\begin{array}{l}\text { Notes: T-statistics reported in parentheses based on standard errors clustered at the importer-city level. The dependent variable, "First Match Status", takes } \\
\text { on the value } 1 \text { in the first year a trans action is observed between a unique exporter-importer pair and is } 0 \text { otherwise. The independent variable is lagged one } \\
\text { year. Importers are categorized into two size bins using average number of employees over the sample period. "Small” refers to } 1-249 \text { employees and } \\
\text { "Large" refers to } 250+\text { employees. Exporters are first classified into three quantiles using averagevalueof total export sales over the sample period. The top } \\
\text { quantile is classified as "Large" and the rest as "Small”. Column (5) only considers observations for cities where HS products } 61 \text { and } 62 \text { are produced. } \\
\text { Column (6) only considers observations for cities thatproduce exclusively bound or unbound products. Bound products are those with quota fill rates } \\
\text { greater than } 90 \text { percent in } 2004 \text {. }\end{array}$} \\
\hline
\end{tabular}


TABLE 5-FiRST MATCH STATUs, 2002-2009, RoBUSTNESS CHECKS

\begin{tabular}{|c|c|c|c|}
\hline \multicolumn{4}{|c|}{ PANEL A: ALTERNATIVE SAMPLES } \\
\hline & $\begin{array}{c}\text { Neighbors }>1 \\
\text { (1) }\end{array}$ & $\begin{array}{l}\text { First Year }>=2002 \\
\text { (2) }\end{array}$ & $\begin{array}{l}\text { Small Exporters } \\
\text { (3) }\end{array}$ \\
\hline \# exporters-importer j, same city (t-1) & 0.000066 & 0.000062 & 0.000032 \\
\hline & $(10.34)$ & $(8.96)$ & $(5.35)$ \\
\hline Observations & $123,622,485$ & $99,455,857$ & $84,902,979$ \\
\hline Importer x Year Fixed Effect & $\mathrm{Y}$ & Y & $\mathrm{Y}$ \\
\hline Exporter x Year Fixed Effect & $\mathrm{Y}$ & $\mathrm{Y}$ & $\mathrm{Y}$ \\
\hline \multicolumn{4}{|c|}{ PANEL B: ALTERNATIVE NETWORK MEASURES } \\
\hline & $(1)$ & $(2)$ & (3) \\
\hline \# exporters-importer j/total exporters, same city (t-1) & $\begin{array}{c}0.104873 \\
(11.03)\end{array}$ & - & - \\
\hline \# exporters-importer j/total importers, same city (t-1) & - & $\begin{array}{l}0.143910 \\
(9.88)\end{array}$ & - \\
\hline \# exporters-importer j, same city (t-2) & - & - & $\begin{array}{l}0.000055 \\
(8.07)\end{array}$ \\
\hline Observations & $131,965,095$ & $131,965,095$ & $113,113,639$ \\
\hline Importer x Year Fixed Effect & $\mathrm{Y}$ & $\mathrm{Y}$ & $\mathrm{Y}$ \\
\hline Exporter x Year Fixed Effect & $\mathrm{Y}$ & $\mathrm{Y}$ & $\mathrm{Y}$ \\
\hline
\end{tabular}

Notes: T-statistics reported in parentheses based on standard errors clustered at the importer-city level. The dependent variable, "First Match Status", takes on the value 1 in the first year a transaction is observed between a unique exporter-importer pair and is 0 otherwise. The independent variable is lagged one year. In Panel A, the samples are restricted in column (1) to observations for which the number of exporters selling to importer $j$ in a city is greater than 1; in column (2) to only exporters who first appear in the LFTTD-IMP in 2002 and after, and in column (3) to "small" exporters. Exporters are first classified into three quantiles using average value of total export sales over the sample period. The top quantile is classified as "large" and the rest as "small". 
TABLE 6-FIRST Match Status, 2002-2009, HeterogeneOUsEFfeCts

\begin{tabular}{ccc}
\hline & $(1)$ & $(2)$ \\
\hline \# exporters-importer j, same city (t-1) & 0.000016 & 0.000089 \\
& $(1.41)$ & $(8.42)$ \\
x Large Exporter & 0.000136 & - \\
x Large Importer & $(4.64)$ & -0.000038
\end{tabular}

Observations
Importer x Year Fixed Effect


TABLE 7-First MATCh StATUs, 2002-2009, EXTENSIONS

\begin{tabular}{lcc}
\hline & Congestion Effects & Competition Effects \\
& $(1)$ & $(2)$ \\
\hline \# exporters-importer j, same city (t-1) & 0.000072 & - \\
Quantile 1 & $(7.82)$ & - \\
Quantile 2 & 0.000091 & - \\
Quantile 3 & $(9.41)$ & 0.000235 \\
Quantile 4 & 0.000088 & $(12.69)$ \\
& $(12.58)$ & -0.000115 \\
X & 0.000061 & $(9.28)$ \\
\# exporters-importer j, same city (t-1) & $(9.69)$ & $131,965,095$ \\
& - & Y \\
& - & Y \\
\hline
\end{tabular}


APPENDIX A

Figure A1-Distribution Of Total EXPORT VALUE, 2002 - 2009

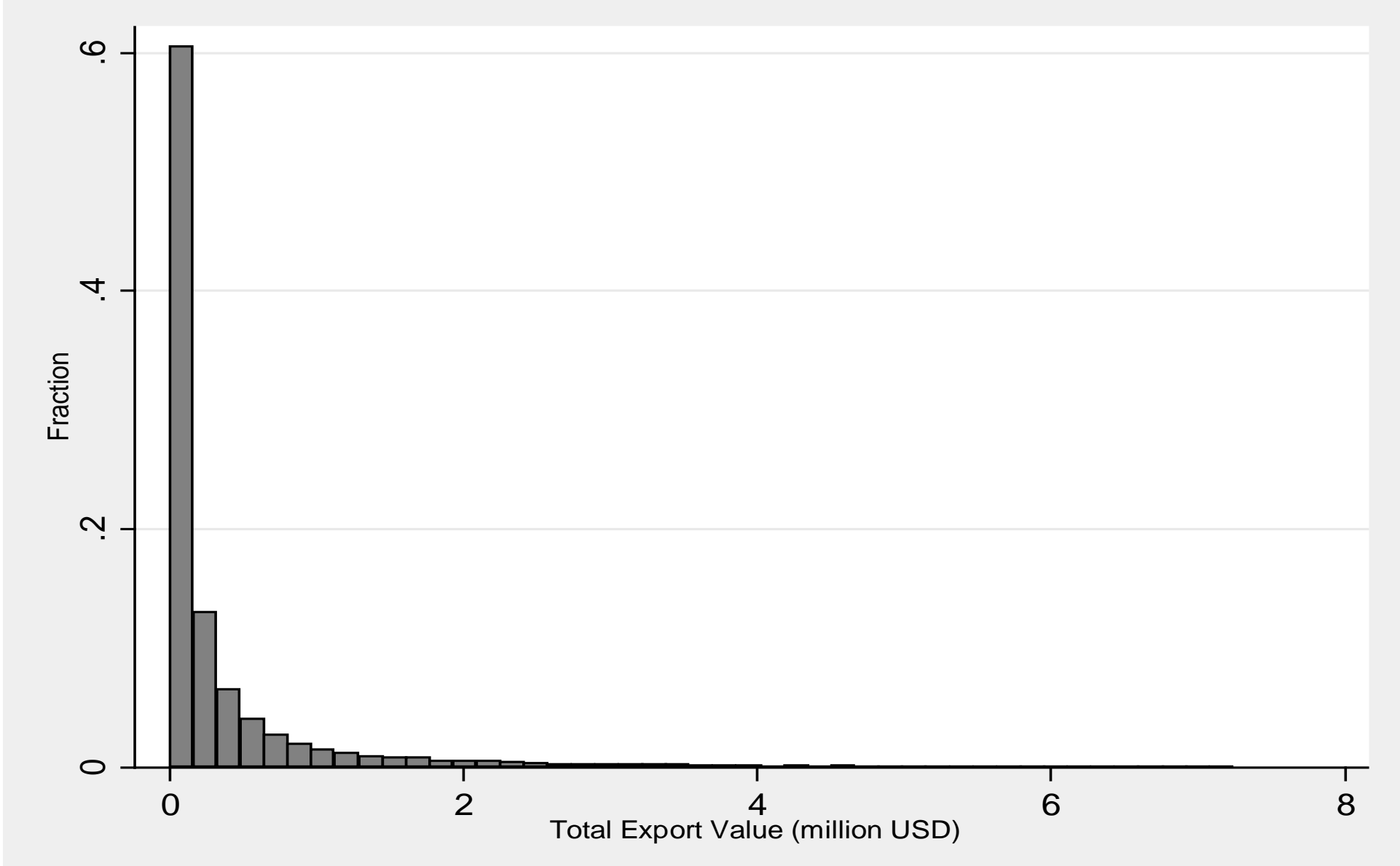

Source: Authors' calculations.

Notes: Values are in current U.S. dollars. 
TABLE A1.EXAM PLES OF MANUFACTURER ID CONSTRUCTION

\begin{tabular}{ccccc}
\hline Country & Exporter Name & Address & City & MANUFID \\
\hline Bangladesh & Red Fabrics & 1234 Tiger Road & Dhaka & BDREDFAB1234DHA \\
Bangladesh & Green Fabrics & 1111 Lion Road & Dhaka & BDGREFAB1111DHA \\
Bangladesh & Blue Fabrics & 88 Zebra Road & Chittagong & BDBLUFAB88CHI \\
\hline Notes: The above examples are based on fictitious names andaddresses and are meant for illustrative purposes only.
\end{tabular}

Notes: The above examples are based on fictitious names and addresses and are meant for illustrative purposes only. 
TABLE A2. First MATCH StATUs, 2002-2009, CONDITIONAL LOGIT

(1)

\# exporters-importer j, same city

$0.031791^{* * * *}$

(0.000)

\begin{tabular}{lc}
\hline Observations & $20,695,095$ \\
Exporter x Year Fixed Effect & $\mathrm{Y}$ \\
Importer Controls & $\mathrm{Y}$ \\
\hline
\end{tabular}

Notes: Robust standard errors in parentheses. Significance at $* 10 \%, * * 5 \%$, *** $1 \%$ level. The dependent variable, "First Match Status", takes on the value 1 in the first year a trans action is observed between a unique exporter-importer pair and is 0 otherwise. The independent variable is lagged one year. Importer controls include logged values of firm age and employment. 
APPENDIX B: Uniqueness of City Information in MID

We extract the Bangladeshi textile manufacturer's location information from the manufacturer identifier (MID) as represented by the last three letters (refer to Appendix A, Table A1 for examples). We create a list of all unique three-letter city codes and then match it against the 2013 geographic administrative codes compiled by the Bangladesh Bureau of Statistics. ${ }^{35}$ Close inspection of the three-letter city list indicates that cities conform roughly to sub-districts (upazilas), the third lowest level of geographic administrative divisions. There are 282 cities in our analysis sample.

It is possible that a three-letter city code could represent multiple cities. For instance, "TAN" could refer to either Tangail or Tanore that are located in Dhaka and Rajshahi divisions, respectively. We ensure that the city codes do not refer to multiple possible cities where textile manufacturers may be located. To this end, we compile a list of all possible sub-districts that correspond to each three-letter city code. We then identify the most likely sub-district using external information on textile manufacturers.

We utilize three external sources of firm information. We compile a list of all member firms belonging to the Bangladesh Garment Manufactures and Exporters Association (BGMEA), Bangladesh Knitwear Manufactures and Exporters Association (BKMEA), and the Bangladesh Textile Mills Association (BTMA) that all include a mailing and factory address for the firm. ${ }^{36}$ BGMEA member factories account for 100\% of total woven garments exports, over 95\% of total sweater exports, and about 50\% of total light knitwear exports from Bangladesh. ${ }^{37}$ These three directories are the most reliable sources of information on Bangladeshi textile manufacturers.

\footnotetext{
${ }^{35}$ See http://www.bbs.gov.bd.

${ }^{36}$ Accessed at http://www.bgmea.com.bd/member/memberlist\#.UnEBEKyAqSo, http://www.bkmea.com/member/index.php, http://www.btmadhaka.com/Mill\%20List.html respectively.

${ }^{37}$ See http://www.bgmea.com.bd/home/pages/AboutBGMEAT\#.UnEBd6yAqSo.
} 
The BGMEA directory has been used as the sample frame for the country specific enterprise surveys conducted by the World Bank (Fernandes, 2008) as well as independent surveys (Klepper and Mostafa, 2009) examining issues specific to the Bangladesh garments industry. The World Bank enterprise survey for Bangladesh utilizes all three directories to form its sample frame. $^{38}$

We generate frequencies of the number of firms for all cities that appear in the directories. Then, we use this information to identify the most likely city represented by the three-letter code where it corresponds to more than one possible city from the list of geographic administrative codes. However, there are instances where a three-letter code corresponds to multiple cities of similar frequencies. For example, the three-letter code "MIR" may correspond to Mirzaganj in Barisal division, Mirsharai in Chittagong division, Mirpur (in Dhaka or Khulna divisions), or Mirzapur in Dhaka division. Both Mirpur and Mirzapur in Dhaka division are likely candidates. We identify three such codes that may correspond to multiple cities where textile manufacturers are located and that together account for about $6 \%$ of the total number of textile exporters in the sample. To confirm the robustness of our results to dropping these cities from our sample, we rerun our baseline specifications excluding firms located in these three cities. Our baseline results remain almost identical in both statistical significance and magnitude.

Additionally, among the three-letter city codes reported in the data, we find that one three-letter code represents about 45 percent of exporters in the sample, leading us to suspect that this particular code corresponds to a district. We thus re-estimate our baseline specification excluding observations corresponding to this code, so that our measure of neighboring exporters

\footnotetext{
${ }^{38}$ See http://siteresources.worldbank.org/INTPSD/Resources/336195-1092412588749/00--Bangladesh--1-78.pdf for detailed discussion.
} 
corresponds to comparable geographic areas. We find that our coefficient remains positive and significant. Results for both sets of robustness checks are available upon request. 


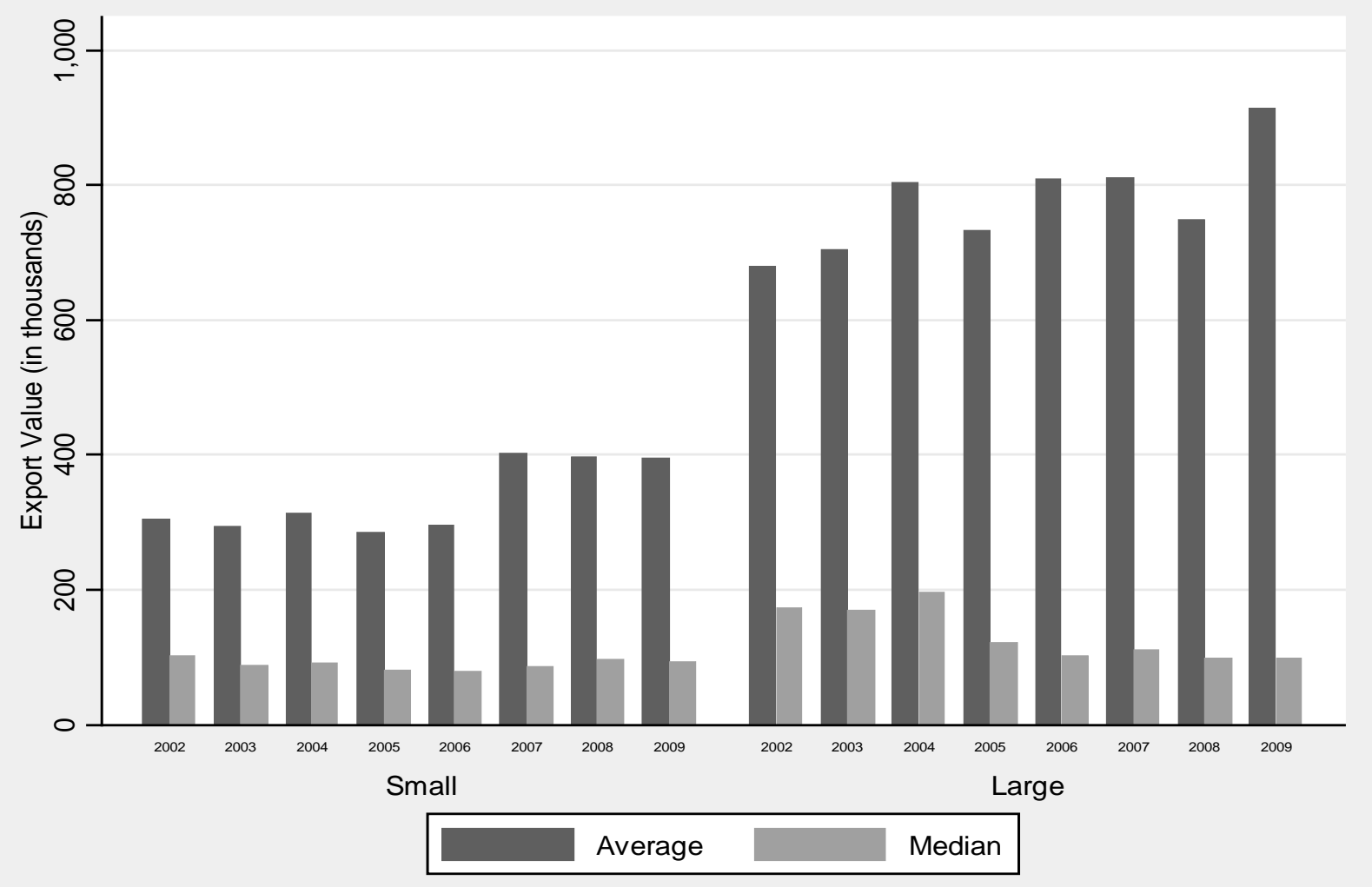

Source: Authors' calculations.

Notes: Importers are categorized into two size bins using average number of employees over the sample period. "Small” refers to importers that employ 1-249 workers and "Large" refers to importers that employ 250+ workers; Values are in current U.S. dollars. 


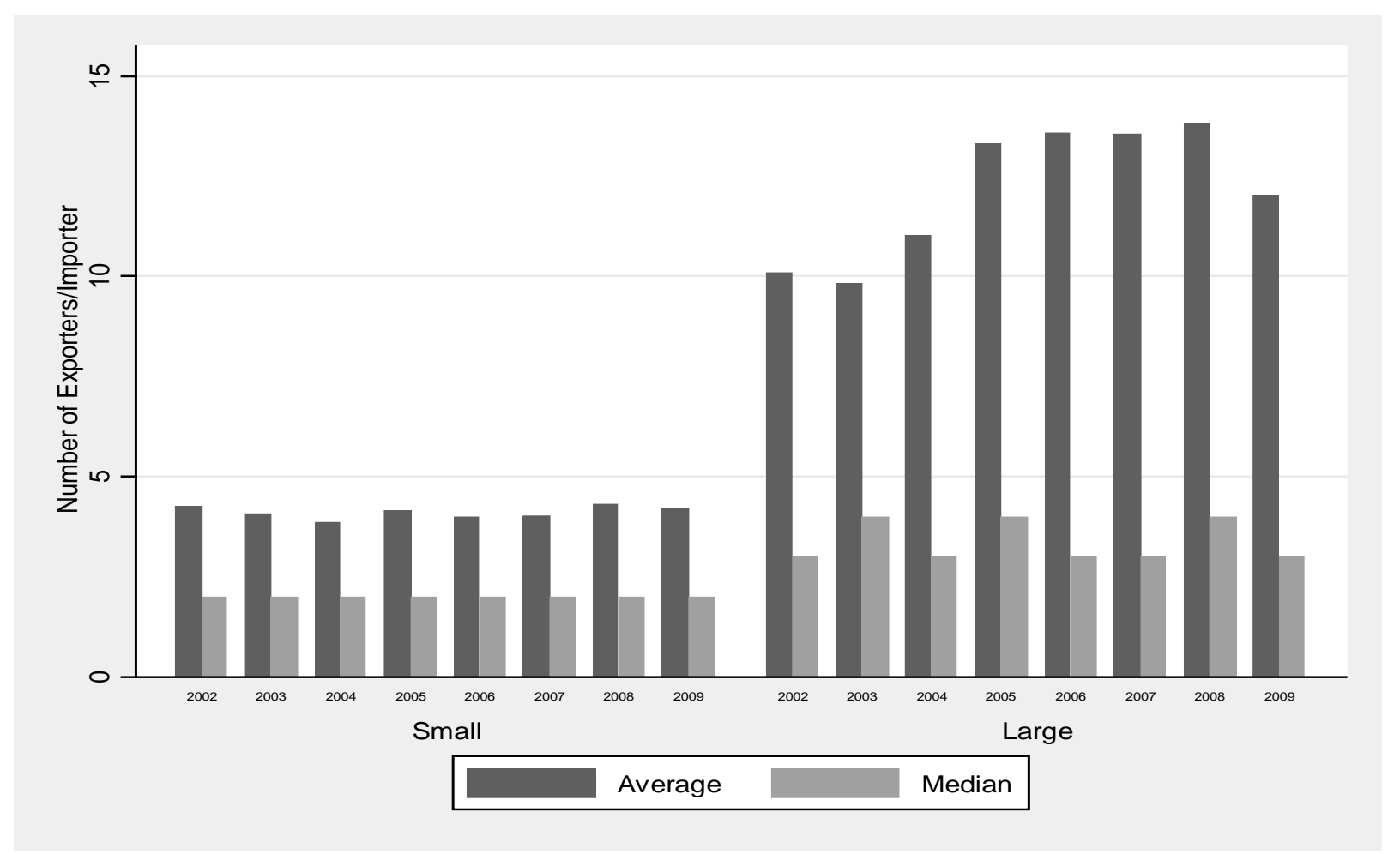

Source: Author's calculation

Notes: Importers are categorized into two size bins using average number of employees over the sample period. "Small” refers to importers that employ 1-249 workers and "Large" refers to importers that employ 250+ workers. 